\title{
Ordenamento do território visando à sustentabilidade
}

\section{Joaquim Francisco de Carvalho Emílio La Rovere}

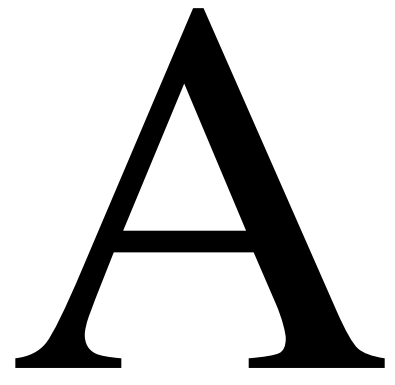

$\mathrm{s}$ alterações relevantes causadas pelo homem no ambiente natural começaram com a agricultura não nômade, que surgiu na Mesopotâmia há cerca de 9 mil anos. Abria-

-se espaço para assegurar a alimentação dos agrupamentos humanos que aos poucos iam se formando - e, também, para fornecer insumos para as primitivas indústrias de cerâmica, tecelagem e metais (basicamente, o cobre). Como as populações eram rarefeitas, aquelas alterações eram tópicas, não se refletindo sensivelmente nos ecossistemas regionais, mais amplos.

Veio depois a cultura irrigada de cereais, que tornou possível o plantio de culturas alimentares em áreas pequenas e acessíveis, oferecendo uma condição prévia para o adensamento populacional.

A primeira forma de urbanização, ou protourbanização, teve raízes religiosas: "Os gregos, assim como os itálicos, acreditavam que a localização de qualquer urbe devesse ser escolhida e revelada pela divindade. Por isso, quando queriam fundar alguma urbe, consultavam sempre o Oráculo de Delfos" (De Coulanges, 1987).

Até meados do século XIX não se cogitava ordenar territórios para a agricultura e para o assentamento das populações. Os conceitos de região e de conurbação só vieram a ser introduzidos pelo biólogo, urbanista e sociólogo escocês Sir Patrick Geddes (1854-1932) em seus trabalhos sobre planejamento urbano, nos quais procurou definir uma unidade de medida comum para explicar as correlações entre o uso de recursos materiais e o desenvolvimento econômico e social. Antes disso, considerava-se que o desenvolvimento da sociedade implicava ocupação desordenada de regiões virgens, derrubadas de florestas, aumento do consumo...

Num ensaio publicado em 2006, o professor José Eli da Veiga observou que

"Foi somente há 70 anos que surgiu a proposta de intervenção deliberada do poder público para induzir a localização de atividades, isto é, para ordenar o território. Hoje praticamente todos os países o fazem de alguma maneira [...] houve significativo progresso nesse propósito de diversificar as políticas governamentais em função das necessidades específicas das regiões, ou de determinadas regiões [...] a biosfera, em nível global, regional, nacional e local, está sendo submetida a pressões insuportáveis e prejudiciais para o próprio desenvolvimento e à qualidade da vida [...]. O ordenamento territorial passou a ter, portanto, sentido bem mais preciso. Visa a organizar o processo de desenvolvimento no território, como alternativa ao puro e simples comportamento dos mercados, que 
tangem os residentes a se deslocarem para encontrar oportunidade de trabalho e geração de renda. Trata-se de uma prática que pode ter perdido legitimidade com a ofensiva neoliberal do final do século XX, mas que já volta com toda a força para as agendas de desenvolvimento [...]. Há pelo menos quatro fatores que explicam essa volta do território ao domínio da ação pública: 1 . ele está no centro das estratégias que visam à competitividade e à atratividade econômicas; 2 . é nele que pode ser reforçada a coesão social; 3 . é o melhor instrumento de modernização das políticas públicas, já que impõe abertura e transversalidade; 4 . apesar de nele estarem ancoradas as instituições locais, permanece um domínio de ação de instâncias hierárquicas superiores cujos graus de liberdade são cada vez mais condicionados pelo processo de globalização e pela construção de acordos regionais supranacionais.

Assim, renovar a concepção de território para uma política de ordenamento exige, antes de tudo, que ele seja entendido como ator de um esforço constante de desenvolvimento, mas de um desenvolvimento no qual a coesão social é simultaneamente uma aposta e uma alavanca. Nesse sentido, três insights têm sido cada vez mais enfatizados: a necessidade de combinar concorrência com cooperação; a necessidade de combinar conflito com participação; e a necessidade de combinar o conhecimento local e prático com o científico" (Veiga, 2006, p. 123).
A partir do voo orbital de Yuri Gagarin, no final dos anos 1950, o público começou a tomar consciência das agressões causadas pelo homem à Terra, que ficaram bem visíveis nas imagens tomadas do espaço, mostrando cidades a lançar nuvens de fumaça e poeira à atmosfera, infraestruturas desordenadas, florestas devastadas e mares poluídos.

A urbanização, que era considerada um indicador de progresso econômico, passou a ser vista de um modo mais seletivo. Começava-se a distinguir explosão urbana de urbanização racionalmente orientada e alguns urbanistas já pensavam em estabelecer ritmos ideais de crescimento, impondo limites ao tamanho das cidades.

Há cerca de trinta anos o historiador e economista Paul Bairoch analisou a questão à luz de condicionantes tais como clima, saúde pública, trânsito, criminalidade, renda, lazer, etc., e procurou definir o efetivo po-

JOAQUIM FRANCISCO DE CARVALHO é doutor em Energia pelo Instituto de Energia e Eletrotécnica da USP e pesquisador do Programa de Planejamento Energético da Coppe/UFRJ.

EMILIO LA ROVERE é professor do Programa de Planejamento Energético da Coppe/UFRJ, onde coordena o Laboratório Interdisciplinar de Meio Ambiente. 
pulacional de uma cidade, acima do qual as vantagens econômicas e sociais da urbanização seriam anuladas pelo agravamento dos problemas de poluição, transportes congestionados, dificuldades de abastecimento, criminalidade e outros (Véron, 2006, pp. 72-3). Paul Bairoch concluiu que o efetivo ótimo estaria entre 300 mil e 600 mil habitantes, para os países desenvolvidos, e entre 200 mil e 500 mil, para os países em desenvolvimento, e estimou que, acima de $500 \mathrm{mil} \mathrm{a} 800 \mathrm{mil}$ habitantes, cancelam-se as vantagens da urbanização.

\section{EXPANSÃO DA FRONTEIRA AGRÍCOLA}

O solo se comporta como se fosse um organismo vivo. Sua fertilidade depende de processos ligados à vida de diversas comunidades de organismos, numa camada superficial que raramente passa de 30 centímetros de espessura. Essa camada é formada pela decomposição, em solo úmido, de matéria orgânica que, ao longo dos séculos, vai se depositando na superfície e repondo o material levado pela erosão natural, que ocorre mesmo em áreas originalmente florestadas ou cobertas de prados, mas o processo é acelerado em áreas em que a vegetação natural é substituída pelas monoculturas de ciclo curto e reflorestamentos industriais.

A reconstituição da camada fértil do solo é muito lenta. Dependendo, entre outros fatores, do relevo e das características geológicas do terreno, estima-se que sejam necessários cerca de duzentos anos para se reconstituir uma camada de apenas um centímetro de espessura (Brown, 1982).

Se a erosão for mais rápida do que a reposição, diz-se que o Fator de Tolerância foi ultrapassado. Mas isso não faz parte do rol de preocupações da maioria dos produtores rurais.

Curiosamente, entretanto, há mais de 2.400 anos Platão parece ter-se preocupado com o fenômeno da erosão. É assim que ele descreve a devastação das terras da Tessália, em seu diálogo Crítias:

"Quanto à excelência do solo, nossa terra superava a todas... a melhor prova disso é que a porção remanescente pode competir com qualquer outra região do mundo, na variedade de seus frutos e na riqueza das pastagens para animais de toda espécie [...]. Mas, além da superioridade dos frutos, a terra então se distinguia por produzi-los em abundância [...] muitas e grandes inundações se fizeram sentir, e com tamanhas revoluções da natureza, sem que durante todo esse período se depositasse a terra deslocada das alturas pelas águas [...] o que resta do passado é como os ossos de um corpo devastado por doenças" (Platão, 2001, pp.160-1).

Solos explorados em rodízio, com rotações anuais (como no método Voisin, por exemplo), preservam a camada superficial de húmus que se acumula pela decomposição de resíduos vegetais, aos quais se juntam restos animais em menor escala, retendo água, fortalecendo a estrutura do solo e evitando a degradação dos lençóis freáticos. Em virtude de suas propriedades coloidais, o húmus é muito importante na constituição do solo, sendo a principal fonte de matéria orgânica para a nutrição das plantas.

Outro aspecto a ser considerado nos planos de ordenamento do território visando à sustentabilidade é a necessidade de se manterem talhões florestais margeando as plantações e nelas intercalados. As florestas são indispensáveis para a estabilização da umidade atmosférica, para o regime pluviométrico e, portanto, para a regularidade de todo o ciclo hidrológico.

As florestas também podem desempenhar um papel importante no controle entomogênico microrregional. Embora esse assunto fuja ao escopo do presente artigo, é interessante lembrar que os insetos considerados como pragas para a agricultura constituem a base das cadeias alimentares dos pássaros, que têm seu habitat nas florestas, mas recolhem a sua alimentação nos campos naturais e nas áreas exploradas pela agropecuária, nos quais podem proliferar as pragas (Pollan, 2006). A manutenção de maciços florestais associados à agricultura é, portanto, um meio muito eficiente para os pássaros limitarem a proliferação de pragas, sem a necessidade de pesticidas de origem petroquímica.

Ordenar a ocupação do território visando à sustentabilidade requer que, em qualquer plano de produção agrícola ou pecuária, os espaços a serem ocupados sejam delimitados nas dimensões suficientes para permitir a manutenção da estrutura dos solos, evitando a sua depauperação.

\section{URBANIZAÇÃO}

O ordenamento do território visando à sustentabilidade exigiria reformulações importantes no conceito de desenvolvimento urbano e nas práticas de implantação das infraestruturas de transportes urbanos e interurbanos. 
A partir de meados do século XIX tem-se intensificado o fluxo de imigração na direção das cidades, provocando um acelerado crescimento do consumo de energia. As cidades já respondem por $75 \%$ do consumo mundial de energia e por $80 \%$ das emissões de gases causadores do efeito estufa.

Uma cidade é, tipicamente, um sistema dissipativo, que depende do equilíbrio da microrregião que está em volta (Prigogine, 1994). Se esta se desequilibrar, a cidade também se desequilibra. Por outras palavras, a sustentabilidade de uma cidade depende do equilíbrio dos fluxos de matéria e energia que entram e saem - e isso é influenciado pelo número de elementos que a formam e por seu regime termodinâmico, ou pelo nível de organização dos referidos elementos, atributos esses que caracterizam a entropia. Cidades sustentáveis produzem pouca entropia e são bem organizadas, enquanto cidades insustentáveis produzem muita entropia e são caóticas. Assim, para que haja sustentabilidade, os fluxos de energia e bens de consumo que entram devem estar equilibrados com os fluxos de resíduos sólidos e emissões líquidas e gasosas que saem (Carvalho, 2011).

Um dos principais obstáculos à transição do atual modelo insustentável para um modelo sustentável está no setor de transportes, tanto o urbano (passageiros), como o interurbano (cargas e passageiros). O problema não se restringe à produção de combustíveis para uma frota mundial em expansão, que pode saltar dos atuais 700 milhões para 2,5 bilhões de automóveis até 2050.

Além da produção e consumo de combustíveis, temos que pensar também nas agressões ao meio ambiente provocadas por toda a cadeia de produção da indústria automobilística e suas satélites (extração de minérios, produção e transformação de diversos metais, plásticos, borrachas, etc.).

Não haveria nada contra a produção de biocombustíveis, desde que fosse em escala razoável. Entretanto, é necessário estabelecer limites para evitar que a produção à outrance de etanol e outros agrocombustíveis de primeira geração agrida ecossistemas naturais ou use terras agricultáveis para plantar cana.

O mesmo vale para os chamados biocombustíveis de segunda geração, constituídos por remanescentes florestais, como caules, galhos e folhagens, além de resíduos orgânicos. E vale, também, para os combustíveis de terceira geração, extraídos de microalgas.

$\mathrm{O}$ reaproveitamento de remanescentes florestais (que é feito pela indústria madeireira) pode ser am- bientalmente favorável, mas o reaproveitamento de resíduos agrícolas, como palhas de milho, arroz e outras, poderá entrar em concorrência com o fornecimento de ração animal.

Se a matéria-prima para os biocombustíveis provier de cultivos de gramíneas de alta produtividade ou de árvores de crescimento rápido, as plantas acelerarão a retirada de elementos minerais do solo, em descompasso com a capacidade de reposição da camada fértil e provocando o seu depauperamento. Além disso, serão ocupadas terras agricultáveis, com mudanças no uso dos solos.

No tocante à terceira geração de biocombustíveis embora as microalgas tenham uma eficiência fotossintética que lhes permite acumular grandes quantidades de óleos e açúcares (convertíveis em biodiesel ou em bioetanol), seu cultivo também requer espaço.

Assim, parece lógico que se deva investir prioritariamente na implantação de sistemas de transportes coletivos de boa qualidade - e transportes de cargas mais eficientes, como o ferroviário e o fluvial - em vez de produzir mais etanol e outros biocombustíveis para abastecer uma crescente frota de automóveis e caminhões.

Os sistemas viários urbanos já se mostram insuficientes para o atual número de automóveis. Em certos casos, já se gasta mais tempo dentro de automóveis e ônibus do que na escola ou no trabalho. Um número elasticamente crescente de automóveis é incompatível com a rigidez das ruas, que, evidentemente, não aumentam de largura. E, mesmo que aumentassem, as cidades não podem ser inteiramente ocupadas por ruas. Os prédios também ocupam espaço, assim como as áreas verdes e aquelas destinadas aos pedestres. Enfim, os atuais modelos são insustentáveis.

Outro problema grave é o da deposição final dos rejeitos da "civilização do automóvel". Os "cemitérios de automóveis" e as montanhas de pneus que vão se acumulando nas proximidades de grandes metrópoles são inaceitáveis.

Em resumo, temos que reformular os modelos de urbanização e transportes de pessoas e cargas - e não aumentar a produção de automóveis e combustíveis. Para reduzir a participação dos biocombustíveis e, principalmente, dos combustíveis fósseis na matriz energética, é necessário que o desenvolvimento das cidades obedeça a rigorosos planos diretores, voltados para a minimização das distâncias de transporte de cargas e para a oferta de transporte coletivo urbano de qualida- 
de, suficiente para deslocar a preferência das pessoas do transporte individual para o transporte do coletivo.

Além da importância da cidade como polo comercial e "cérebro" de praticamente todas as iniciativas industriais e de produção em geral, não se pode perder de vista aquilo que é, provavelmente, a sua função mais importante, que é a de centro cultural e viveiro de criação artística e científica. É necessário reformular os modelos urbanos para atender a esses requisitos.

Idealmente, um efetivo populacional ótimo a ser procurado pelos urbanistas seria aquele sugerido por Paul Bairoch (efetivo populacional entre 200 mil e 800 mil habitantes). Assim, um modelo urbano ideal observaria uma configuração como a seguinte, por exemplo:

- centro administrativo/cultural/residencial, com cerca de 200 mil habitantes, que abrigaria boa parte da população do complexo urbano;

- bairros residenciais e "núcleos administrativos/culturais/comerciais descentralizados", em número de quatro, com algo em torno de 150 mil habitantes cada um, de modo que a conurbação inteira teria 800 mil habitantes.

A mobilidade na conurbação seria assegurada por linhas de metrô e vias expressas.

As distâncias de transporte de gêneros para abastecer o conglomerado seriam consideravelmente reduzidas mediante a implantação de explorações agrícolas em zonas estrategicamente localizadas na microrregião circundante, num modelo de produção local que favorece a economia de combustíveis (Barghini, 2009). Em alguns casos seria possível implantar núcleos de "agricultura urbana" (Friedman, 1998), em cinturões verdes especialmente reservados para isso, em torno dos bairros residenciais.

A figura que ilustra este artigo é autoexplicativa. Nela é idealizado um esboço (muito simplificado) de "conurbação de baixa entropia", concebida para atender aos requisitos mencionados acima.

Previu-se, nesse esboço, um centro administrativo/cultural/residencial limitado a 200 mil habitantes (CCAR), que abrigaria uma parte da população do complexo urbano, em especial os funcionários das repartições públicas, professores, estudantes, artistas, bancários e comerciários empregados no centro.

Os bairros residenciais e "núcleos administrativos/ culturais/comerciais/residenciais descentralizados" (NACD/BRACS), em número de quatro, teriam 150 mil habitantes cada um, de modo que a conurbação inteira teria 800 mil habitantes, ficando na faixa de sustentabilidade, preconizada por Paul Bairoch.

Naturalmente, tal esboço só pode indicar diretrizes para cidades em início de formação.

No caso de cidades antigas - que cresceram e se agigantaram sob o ditado da especulação imobiliária e na perspectiva do transporte individual -, as dificuldades causadas pelo crescimento caótico vão fazendo com que os próprios cidadãos, individualmente ou através de ONGs, associações de moradores, conselhos profissionais e outras organizações, comecem a se informar seriamente sobre o problema e a pressionar o poder público no sentido de influir na formulação de políticas relacionadas às questões urbanas.

Durante a Rio +20 foram debatidos diversos temas ligados a novas experiências de governança urbana, redes de colaboração civil, desenvolvimento sustentável, compartilhamento de infraestruturas urbanas, etc.

Pesquisadores ligados ao Instituto de Políticas para Transporte e Desenvolvimento (cuja sigla inglesa é ITDP) apresentaram seu programa de transferência de conhecimento técnico para a modernização dos sistemas de transporte e para a formulação de políticas públicas para o setor, principalmente em países em desenvolvimento.

Alguns municípios brasileiros, como São Paulo e Rio de Janeiro, por exemplo, começam a adotar políticas públicas orientadas segundo linhas que, em médio e longo prazo, poderão levar esses conglomerados a se aproximarem de modelos mais equilibrados, como o esboçado neste artigo.

Em São Paulo, o chamado projeto "Arco do Futuro" baseia-se em mudanças de zoneamento destinadas a alterar a lógica de crescimento da cidade com vistas à criação de vagas de trabalho em bairros distantes do centro expandido.

Com isso, pretende-se equilibrar as ofertas de moradia e empregos em uma mesma região da cidade, evitando longos deslocamentos e elevando a qualidade de vida da população. Esse projeto é fruto de uma colaboração da Prefeitura Municipal com a Faculdade de Arquitetura e Urbanismo da USP.

No Rio de Janeiro instituiu-se - por iniciativa de representantes de associações de moradores, conselhos profissionais, clubes de serviço, sindicatos, algumas ONGs e cidadãos, em caráter individual - um Fórum Permanente da Mobilidade Urbana na Região Metropolitana. 
Nos dezenove municípios que compõem esse conglomerado constata-se um gradativo aumento no tempo de viagem dos usuários. As cidades e bairros da região separam-se em duas categorias, uma com transporte razoável, e outra com transporte inaceitável. Todos os meios de transporte dependem de concessões públicas.

O Fórum Permanente da Mobilidade Urbana na Região Metropolitana do Rio de Janeiro propõe-se a acompanhar a questão do transporte público e suas variantes em toda a região, elaborar diagnósticos, repercutir discussões, apontar soluções, verificar a eficácia das providências tomadas pelos gestores públicos responsáveis de cada setor e divulgar para a sociedade, principalmente pelas redes sociais, todas as informações necessárias para que todos possam resistir à forte influência dos grupos que detêm as concessões.

\section{CONSIDERAÇÕES FINAIS}

O objetivo deste artigo foi, essencialmente, o de trazer à reflexão de urbanistas e profissionais dos setores energético, agrícola e de transportes, um requisito importante para o desenvolvimento sustentável, qual seja, a sustentabilidade espacial do desenvolvimento.

Em sua contribuição para a preparação da Rio 92, I. Sachs (1992) já a incluía ao lado das dimensões econômica, social, ecológica e cultural/tecnológica do desenvolvimento sustentável.

O diagnóstico da insustentabilidade do desenvolvimento sem a devida ordenação espacial dos assentamentos humanos e das atividades econômicas no território, lembrado neste artigo, remonta aos estruturalistas, reunidos na Cepal após a Segunda Guerra Mundial: o conceito de centro/periferia, cunhado por Raul Prebisch, aplica-se não somente em escala internacional, mas também em regiões internas de um mesmo país (Sunkel, 1981).
O fluxo de matérias-primas da periferia para o centro, e de produtos acabados do centro para a periferia, se dá entre os países em desenvolvimento e os industrializados, mas também entre as regiões menos industrializadas e as mais avançadas de cada país. Isso se repete nas metrópoles e suas áreas de influência, onde se verifica também o deslocamento diário de pessoas para seus locais de trabalho e para desfrutarem dos serviços disponíveis nas metrópoles. Esse perfil de organização espacial gera uma grande demanda de energia associada às necessidades de transporte de mercadorias e passageiros, especialmente em países maldotados de infraestrutura de transporte ferroviário/hidroviário de cargas e de transporte coletivo de passageiros: o transporte rodoviário se torna então predominante, acarretando um intenso consumo de 
combustíveis fósseis derivados de petróleo, com todas as suas externalidades ambientais negativas bem conhecidas.

Assim, é fundamental para um desenvolvimento mais sustentável a implantação de políticas públicas que busquem atuar sobre um dos determinantes mais importantes da demanda de energia e de transportes: o ordenamento do território (La Rovere, 1986).

Deve-se reconhecer as enormes dificuldades nesse sentido, podendo-se citar, dentre outras:

- a busca da forma e do tamanho da cidade ideal foi tema de exaustivas controvérsias entre urbanistas e planejadores regionais, e não há um consenso a esse respeito;

- é conhecida a dificuldade de se influenciarem os padrões de distribuição da população pelo território: nem o planejamento centralizado da União Soviética foi capaz de conter o fluxo migratório para Moscou, mesmo com os mecanismos de coerção utilizados por um regime autoritário;
- a infraestrutura de transporte ferroviário e hidroviário demanda investimentos de muito maior porte que o transporte rodoviário, colocando grandes obstáculos a seu financiamento em países em desenvolvimento.

Entretanto, o Estado dispõe de um arsenal de instrumentos de política econômica (preços, taxas, incentivos fiscais, linhas de crédito, por exemplo) e normativa (leis, planos diretores, critérios de licitações públicas, entre outros) que pode ser utilizado para superar esses obstáculos.

Se esse arsenal for empregado de forma inteligente, será possível consolidar um conceito de urbanização que reúna o campo com a cidade para formar conurbações socioambientalmente sustentáveis. Cabe à sociedade civil organizar-se e exigir do Estado a mobilização desses instrumentos para procurar reverter o agravamento da crise urbana, promovendo um ordenamento do território e uma urbanização mais sustentáveis.

A Rio+20 ofereceu uma excelente oportunidade para um avanço importante nesse sentido.

\section{BIBLIOGRAFIA}

BARGHINI, A. "II Territorio fra Alimenti ed Energia”, in La Rivincita delle Campagne. A cura di Corrado Barberis. Roma, Donzelli Editore, 2009, pp. 269-80.

BROWN, L. A Construção da Sociedade Auto-Sustentável. Tradução de L. Navarro Jr. São Paulo, s. e., 1982.

CARVALHO, J. F. "Measuring Economic Performance, Social Progress and Sustainability Using an Índex", in Renewable and Sustainable Energy Reviews, 15, 2011.

DE COULANGES, F. A Cidade Antiga. São Paulo, Martins Fontes, 1987.

FRIEDMAN, Y. Alternatives Energétiques ou la Civilisation Paysanne Modernisée. St-Jean-de-Braye, Dangles, 1998.

LA ROVERE, E. L. “Um Enfoque Alternativo para o Planejamento Energético”, in Revista ABG, n. 5. São Paulo, junho 1986, pp. 28-32.

PLATÃO. Crítias. Tradução de C. A. Nunes. Belém, Editora da UFPA. 2001.

POLLAN, M. The Omnivore's Dilemma. New York, Penguin, 2006.

PRIGOGINE, I. Les Lois du Chaos. Paris, Flammarion, 1994.

SACHS, I.; "Equitable Development on a Healthy Planet - Transition Strategies for the 21st Century", report to the Unced Secretariat, January 1992.

SUNKEL, O. La Dimensión Ambiental en los Estilos de Desarrollo de America Latina", Cepal -

Programa de las Naciones Unidas para el Medio Ambiente. Santiago de Chile, PNUMA, 1981.

VEIGA, J. E. "Territórios para um Desenvolvimento Sustentável", in Ciência e Cultura, vol. 58, n. 1, jan./mar. 2006.

VERON, J. L'Urbanisation du Monde. Paris, Éditions La Découverte, 2006. 